Electronic spectra of oxygen containing polycyclic hydrocarbon cations and the protonated analogues

Arghya Chakraborty, Jan Fulara, and John P. Maier'

Citation: The Journal of Chemical Physics 143, 084312 (2015); doi: 10.1063/1.4929484

View online: http://dx.doi.org/10.1063/1.4929484

View Table of Contents: http://aip.scitation.org/toc/jcp/143/8

Published by the American Institute of Physics

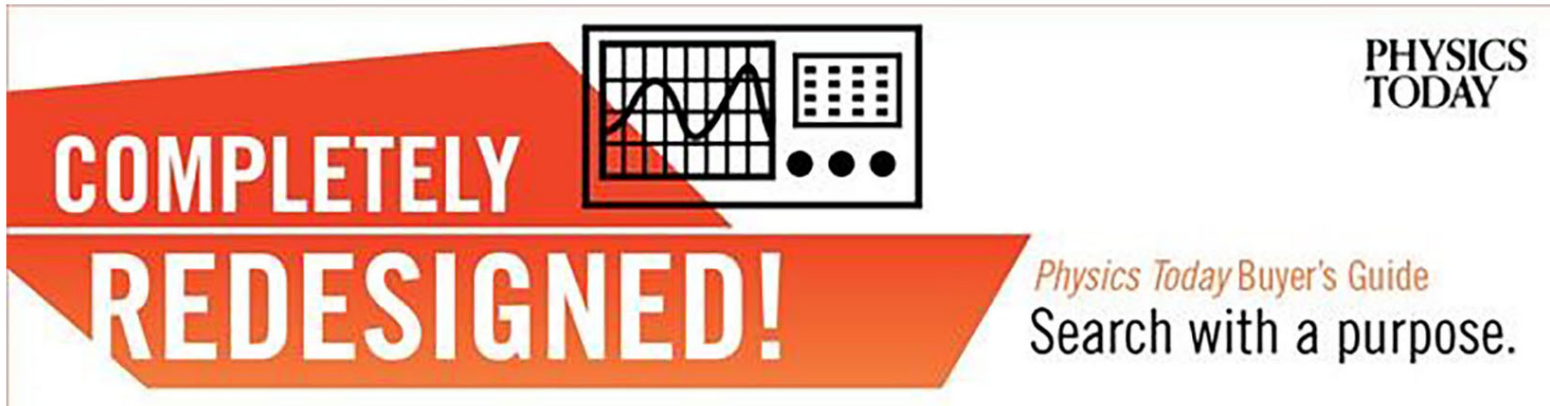




\title{
Electronic spectra of oxygen containing polycyclic hydrocarbon cations and the protonated analogues
}

\author{
Arghya Chakraborty, ${ }^{1}$ Jan Fulara, ${ }^{1,2}$ and John P. Maier ${ }^{1, a)}$ \\ ${ }^{1}$ Department of Chemistry, University of Basel, Klingelbergstarasse 80, CH-4056 Basel, Switzerland \\ ${ }^{2}$ Institute of Physics, Polish Academy of Sciences, Al. Lotników 32/46, PL-02-668 Warsaw, Poland
}

(Received 9 June 2015; accepted 5 August 2015; published online 28 August 2015)

\begin{abstract}
The electronic transitions of 9-fluorenone $\mathbf{F L}^{+}$and 2,3,6,7-dibenzotropone $\mathbf{D B T}{ }^{+}$cations were detected in $6 \mathrm{~K}$ neon matrices following a mass-selective deposition. The absorptions at 649.2 and 472.2 $\mathrm{nm}$ are assigned to the $2{ }^{2} \mathrm{~B}_{1} \leftarrow \tilde{\mathrm{X}}^{2} \mathrm{~A}_{2} \mathbf{F L}^{+}$and $2{ }^{2} \mathrm{~A}^{\prime} \leftarrow \tilde{\mathrm{X}}^{2} \mathrm{~A}^{\prime} \mathbf{D B T}^{+}$transitions. Absorption spectra of protonated 9-fluorenone $\mathbf{H}^{+}$-FL and 2,3,6,7-dibenzotropone $\mathbf{H}^{+}$-DBT have also been measured. Protonation of the oxygenated polycyclic aromatic hydrocarbons is carried out in a hot cathode source via in situ produced protonated ethanol. Vibrationally resolved absorptions commencing at $423.3 \mathrm{~nm}$ of $\mathbf{H}-\mathbf{F L}^{+}$and two band systems of $\mathbf{H}-\mathbf{D B T}^{+}$with origins at 502.4 and $371.5 \mathrm{~nm}$ are assigned to the $2{ }^{1} \mathrm{~A}^{\prime} \leftarrow \tilde{\mathrm{X}}^{1} \mathrm{~A}^{\prime}$ electronic transition of 9-hydroxy-fluorenyl cation and $1{ }^{1} \mathrm{~A} \leftarrow \tilde{\mathrm{X}}^{1} \mathrm{~A}, 2{ }^{1} \mathrm{~A} \leftarrow \tilde{\mathrm{X}}{ }^{1} \mathrm{~A}$ of 2,3,6,7-dibenzocycloheptenol cation. The assignments are based on vertical excitation energy calculations with time dependent density functional theory, symmetry adapted cluster configuration interaction, and MS-CASPT2 methods. (C) 2015 AIP Publishing LLC. [http://dx.doi.org/10.1063/1.4929484]
\end{abstract}

\section{INTRODUCTION}

A significant portion of carbon in interstellar medium is supposed to be in the form of polycyclic aromatic hydrocarbons (PAHs). The broad infrared emission features detected from various astronomical environments, the unidentified infrared emission bands (UIR), are often assigned to vibrational transitions of PAHs and their ions. ${ }^{1-6}$ In dense molecular clouds or disks of young stellar objects where temperatures are low 10-20 K, PAHs are believed to be condensed on interstellar grains as part of molecular ices, containing mainly water. It is expected that the grain surface could be an important site for prebiotic chemistry. Therefore, laboratory exploration of PAHs on cosmic ice analogs upon ultra-violet radiation became a topic in astrochemistry, and several experiments were carried out by varying the temperature, size of aromatics, and using ice of different molecules (e.g., $\mathrm{H}_{2} \mathrm{O}, \mathrm{O}_{2}, \mathrm{CO}_{2}, \mathrm{HCN}$, $\left.\mathrm{NH}_{3}\right) \cdot{ }^{7-12}$ The results demonstrate that ices modify the organics and even create new systems during radiation. In the case of $\mathrm{H}_{2} \mathrm{O}$ mantels, formation of ketones and alcohols of the corresponding PAHs is predominant. ${ }^{8,10}$

As closed shell PAHs generally have the strongest absorption more to the UV region, their radical cations $\left(\mathrm{PAH}^{+} \mathrm{s}\right)$ and isoelectronic protonated analogues $\left(\mathrm{H}^{-} \mathrm{PAH}^{+} \mathrm{s}\right)$ became a subject for spectroscopy and quantum chemistry. ${ }^{13}$ These experimental and theoretical studies revealed that most of the $\mathrm{H}-\mathrm{PAH}^{+} \mathrm{s}$ and $\mathrm{PAH}^{+} \mathrm{s}$ have their strongest absorption in the visible, which may be relevant as possible diffuse interstellar band (DIB) carriers. However, recently measured gas-phase spectra of protonated pyrene and coronene do not correspond to any DIBs. ${ }^{14,15}$ In this context, oxygenated analogs of PAHs have not been much studied except for few photoelectron spectra. ${ }^{16}$ Oxygen containing PAHs (O-PAHs) could be present

\footnotetext{
a) Author to whom correspondence should be addressed. Electronic mail: j.p.maier@unibas.ch. Tel.: +41612673826. Fax: +41612673855.
}

in astronomical environments as incorporation of oxygen is apparent from the UV photolysis of PAHs in solid $\mathrm{H}_{2} \mathrm{O}$. $\mathrm{Ar}$ omatic ketones have been reported in meteorites ${ }^{17,18}$ and solid state ${ }^{1} \mathrm{H}$ and ${ }^{13} \mathrm{C}$ NMR measurement on meteoritic organic matter reveals the presence of aromatic species along with oxidized sp ${ }^{2}$ carbon. ${ }^{19}$

In addition to the possible astrophysical importance, O-PAHs are also detected in the soot of woods and organic oils. ${ }^{20,21}$ The percentage of oxygen containing species is dependent on the airflow and temperature. ${ }^{22}$ Oxygen atoms can be incorporated in reactions with molecular oxygen or in situ from carbon oxides. Hence, the spectroscopic characterization of the O-PAH class of species is of interest for their formation mechanism during terrestrial combustion processes.

In this paper the electronic absorption spectra of two O-PAHs, 9-fluorenone $\mathbf{F L}^{+}$, and 2,3,6,7-dibenzotropone $\mathbf{D B T}^{+}$ cations and their corresponding protonated species $\mathbf{H}-\mathbf{F L}^{+}$and H-DBT ${ }^{+}$are reported. Electronic spectra were recorded after mass selected deposition of ions in $6 \mathrm{~K}$ neon matrices. The assignment of the transitions is made on the basis of calculated excitation energies with the symmetry adapted cluster configuration interaction (SAC-CI), time dependent density functional theory (TD DFT), MS-CASPT2 methods.

\section{EXPERIMENTAL}

The proton transfer technique is an energetically soft approach applied in mass spectrometry. The solid precursor, 9-fluorenone FL, or 2,3,6,7-dibenzotropone DBT, was heated in an oven and carried to the source by ethanol EtOH vapor which served as the protonating agent. The structures of the precursors are shown in Chart 1 . The protonated O-PAHs are produced in the source in situ via protonated ethanol $\mathrm{EtOH}_{2}^{+}$. It has been previously demonstrated that high pressure of $\mathrm{EtOH}$ vapor in the source favors the formation of $\mathrm{EtOH}_{2}^{+}$and as a 


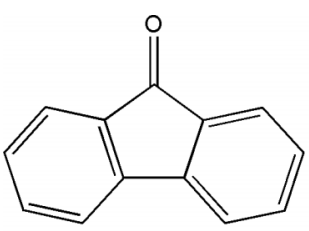

9-fluorenone (FL) $\mathrm{m} / \mathbf{z}=180$

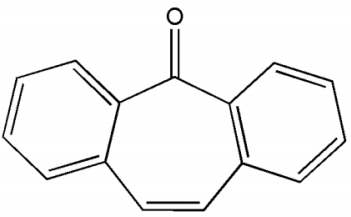

2,3,6,7-dibenzotropone (DBT) $\mathrm{m} / \mathbf{z}=\mathbf{2 0 6}$

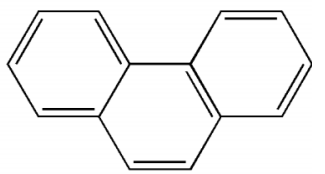

Phenanthrene (PH) $\mathbf{m} / \mathbf{z}=178$
CHART 1. Structure of the precursor molecules. consequence the production of protonated $\mathrm{PAH} .{ }^{23}$ In vapor of pure O-PAHs, the molecular ion $\mathrm{M}^{+}$had the highest intensity in the mass spectrum while the $\mathrm{M}^{+}+1$ signal grew with $\mathrm{EtOH}$ presence (Figure 1). The ions produced were extracted by electrostatic lenses, deflected by $90^{\circ}$ to separate cations from neutrals, and guided into a quadrupole mass-filter. The massselected ions (1 amu resolution) were co-deposited with excess of neon atoms on the surface of a rhodium coated sapphire substrate held at $6 \mathrm{~K}$. The host neon was contaminated by $\mathrm{CH}_{3} \mathrm{Cl}$ in a ratio $30000: 1$ to improve the trapping of cations. Free electrons become available in the matrix by the impingement of ions on metal walls near the substrate. These are captured by the $\mathrm{CH}_{3} \mathrm{Cl}$ scavenger followed by dissociation into $\mathrm{CH}_{3}{ }^{\bullet}$ and $\mathrm{Cl}^{-}$. Presence of $\mathrm{Cl}^{-}$favors the deposition of cations by decreasing the space charge during matrix growth. The $\mathrm{CH}_{3}{ }^{\bullet}$ and $\mathrm{Cl}^{-}$fragments do not absorb in the experimental detection range; the range for spectral measurement is $250-1100 \mathrm{~nm}$. Electronic spectra are recorded normally after accumulation of at least $10-15 \mu \mathrm{C}$ of ions in matrix. The absorptions were measured by a "wave-guide" technique. ${ }^{24}$ Broad band light from two sources, halogen or a high pressure xenon lamp, was passed through the $20 \mathrm{~mm}$ path length of the matrix, then collected by optical fibers, wavelength dispersed by a spectrograph and recorded by the CCD cameras.

\section{COMPUTATION}

9-fluorenone FL and 2,3,6,7-dibenzotropone DBT have five and six non-equivalent protonation sites, respectively. Computational data are needed for the determination of the

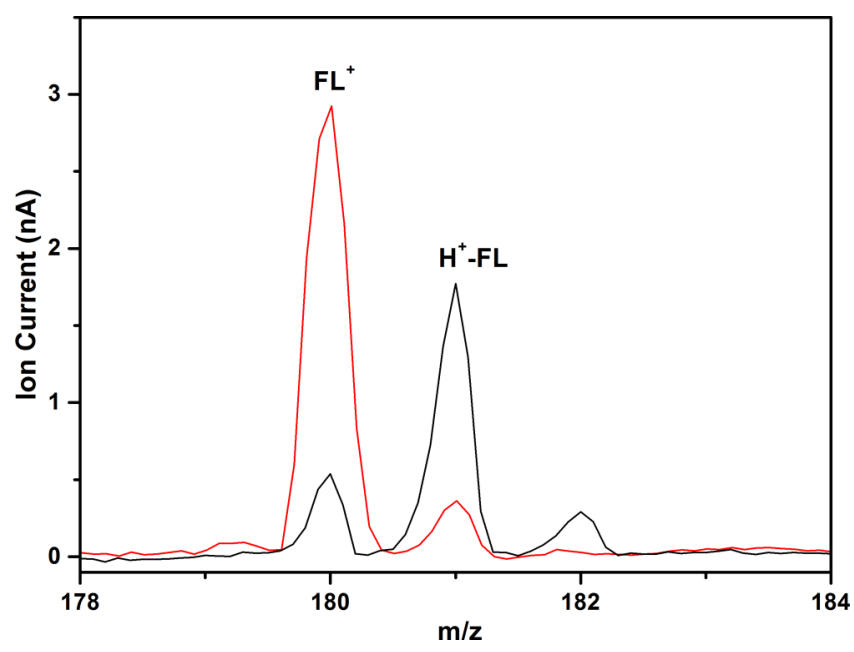

FIG. 1. Section of the mass spectrum of 9-fluorenone FL vapor (red) and in the presence of ethanol (black) in the hot cathode discharge source. most stable protonation site as well as for the assignment of the carriers of the absorptions. Ground state optimization of the plausible protonated isomers of $\mathbf{H}-\mathbf{F L}^{+}$and $\mathbf{H}-\mathbf{D B T}{ }^{+}$was carried out with the DFT method using a cc-pVDZ basis set and the hybrid B3LYP functional in the Gaussian 09 programme. ${ }^{25}$ Relative ground state energies for the $\mathbf{H}-\mathbf{F L}^{+}$isomers $\left[\mathbf{A}^{+}-\mathbf{E}^{+}\right]$ are listed in Chart 2. Isomer $\mathbf{A}^{+}$with proton attached to the oxygen atom is found to be the most stable and $\mathbf{C}^{+}$is next, $75 \mathrm{~kJ} / \mathrm{mol}$ to higher energy. A similar tendency is observed for $\mathbf{H}$-DBT ${ }^{+}$; among the six $\mathbf{F}^{+}-\mathbf{K}^{+}$isomers $\mathbf{F}^{+}$obtained by protonating the oxygen atom of DBT is found as the global minimum. The next stable $\mathbf{E}^{+}$is found $105 \mathrm{~kJ} / \mathrm{mol}$ higher in energy (Chart 2). Therefore, the most stable structures: $\mathbf{A}^{+}$ and $\mathbf{F}^{+}$, designated as $\mathbf{H}-\mathbf{F L}^{+}$and $\mathbf{H}-\mathbf{D B} \mathbf{T}^{+}$, were selected for excitation energy calculations.

The coordinates of $\mathbf{F L}^{+}, \mathbf{H}-\mathbf{F L}^{+}, \mathbf{D B T}^{+}, \mathbf{H}-\mathbf{D B T} \mathbf{T}^{+}$and their neutral counterparts were optimized with the DFT method using the correlation consistent (cc-pVTZ) basis set and the M06-2X functional, ${ }^{26}$ which is more suitable to PAHs due to inclusion of dispersive effects. ${ }^{27}$ These coordinates were used for the calculations of vertical excitation energies. A real minimum was found for $\mathbf{D B} \mathbf{T}^{+}$in $\mathrm{C}_{\mathrm{S}}$ symmetry, which lies $2.0 \mathrm{~kJ} / \mathrm{mol}$ below the $\mathrm{C}_{2 \mathrm{~V}}$ structure. Nevertheless, the $\mathrm{C}_{2 \mathrm{~V}}$ geometry was also used for the excitation energy calculations.

Vertical excitation energies were calculated with TD DFT, SAC-CI ${ }^{28,29}$ implemented in Gaussian 09, and MS-CASPT2 methods $;{ }^{30}$ the latter uses the Molcas software. ${ }^{31}$ In the SAC-CI calculations, the cc-pVDZ basis set was used and about 200 orbitals with an energy $<3$ Hartree were exploited. In CASPT2 calculations state averaging was utilized; wavefunctions were optimized for the mean energy of the electronic states computed (usually 5-8 depending on symmetry of molecule). An active space was constructed from twelve electrons distributed over twelve orbitals $(12,12)$ in the case of singlets and $(11,12)$ for doublets with the exception of $\mathbf{H}-\mathbf{D B} \mathbf{T}^{+}$where the active space was reduced to $(10,10)$.

\section{RESULTS AND DISCUSSION}

\section{A. 9-fluorenone cation and protonated 9-fluorenone}

Spectra recorded after mass-selected deposition of the 9-fluorenone $\mathbf{F L}^{+}$cation with neon including a trace of $\mathrm{CH}_{3} \mathrm{Cl}$ reveal four moderately intense absorption features in the 580$660 \mathrm{~nm}$ range. The strongest band is apparent at $649.2 \mathrm{~nm}$ and three weaker ones lying 211,419 , and $1463 \mathrm{~cm}^{-1}$ to higher energy (Figure 2, red trace). Thereafter, the matrix was exposed to $\lambda<260 \mathrm{~nm}$ photons which cause detachment of electrons from $\mathrm{Cl}^{-}$. Electrons migrate in solid neon at $6 \mathrm{~K}$ and neutralize cations. The same rate of decrement of band intensities after 


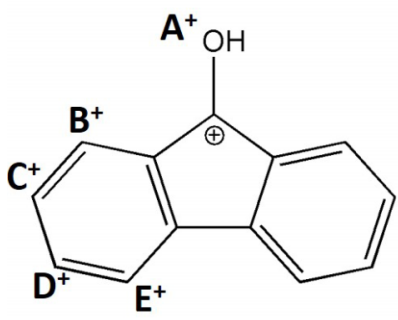

Protonated 9-fluorenone ( $\left.\mathrm{H}^{+}-\mathrm{FL}\right)$

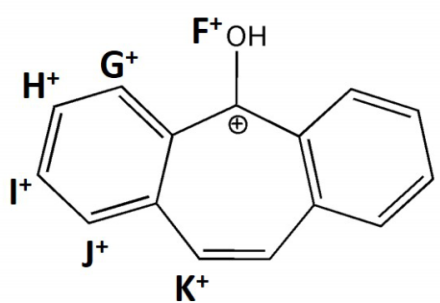

Protonated 2,3,6,7-dibenzotropone ( $\left.\mathrm{H}^{+}-\mathrm{DBT}\right)$
CHART 2. Structure and relative ground state energies $(\mathrm{kJ} / \mathrm{mol})$ of the H-FL $^{+}$and $\mathbf{H}-$ DBT $^{+}$isomers, calculated with DFT using the cc-pVDZ basis set and the B3LYP hybrid functional. irradiation (black trace) indicates that all of them belong to one $649 \mathrm{~nm}$ system and the carrier is cationic (Table I). No new bands appeared after irradiation suggesting that neutral 9-fluorenone FL has absorptions beyond the detection range. The strongest transition of FL has been detected around $245 \mathrm{~nm}$ in solvents. ${ }^{32,33}$

FL has been previously studied by photoelectron (PE) spectroscopy. ${ }^{34}$ The PE spectrum reveals a triplet structure at $0.86,0.99$, and $1.18 \mathrm{eV}$ and a distinct band at $1.91 \mathrm{eV}$ above the ground state of $\mathbf{F L}^{+}$. Vertical excitation energies of $\mathbf{F L}^{+}$were calculated (Table II) with TD DFT, SAC-CI, and MS(5)-CASPT2 $(11,12)$ methods to assign the detected electronic absorptions in the current matrix experiment. All three methods predict low-lying electronic states $1^{2} \mathrm{~A}_{2}, 1^{2} \mathrm{~B}_{1}$, $1{ }^{2} \mathrm{~B}_{2}$ above the $\tilde{\mathrm{X}}^{2} \mathrm{~A}_{2}$ ground state with energies close to the derived ones by PE study. A strong electronic transition with oscillator strength $\mathrm{f}=0.15-0.30$ to the $2{ }^{2} \mathrm{~B}_{1}$ state with energy $2.10-2.35 \mathrm{eV}$ agrees well with the observation at $649 \mathrm{~nm}(1.91$ $\mathrm{eV})$; the band $1.91 \mathrm{eV}$ above the ground state of the ion seen in PE spectrum corresponds to this $2{ }^{2} \mathrm{~B}_{1} \leftarrow \tilde{\mathrm{X}}^{2} \mathrm{~A}_{2}$ transition.

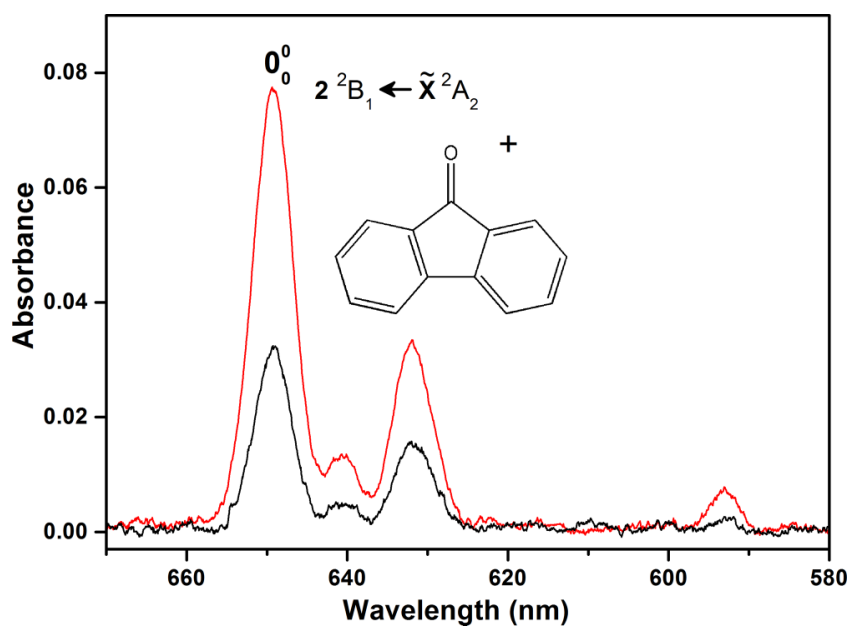

FIG. 2. Electronic absorption spectrum recorded after deposition of 9-fluorenone cation $\mathbf{F L}^{+}$into a neon matrix (red trace) and after neutralization of the cations with UV photons $\lambda<260 \mathrm{~nm}$ (black trace).
The TD DFT and CASPT2 calculations predict also a strong $3^{2} \mathrm{~B}_{1} \leftarrow \tilde{\mathrm{X}}^{2} \mathrm{~A}_{2}$ transition between 3.1 and $3.4 \mathrm{eV}$ which has not been observed experimentally. TD DFT and CASPT2 likely overestimated the $f$ values. A discussion on the theoretical methods is given in supplementary material. ${ }^{38}$

The three vibrational bands apparent in the spectrum are due to excitation of the $v_{21}, v_{20}$, and $v_{9}$ totally symmetric modes in the $2{ }^{2} \mathrm{~B}_{1}$ excited electronic state of $\mathbf{F L}^{+}$. The assignment

TABLE I. Absorption band maxima $( \pm 0.1 \mathrm{~nm})$ of electronic transitions of 9-fluorenone cation $\mathbf{F L}^{+}$and protonated fluorenone $\mathbf{H}^{+}-\mathbf{F L}$ in $6 \mathrm{~K}$ neon matrices and assignment based on the vibrational frequencies of the normal modes listed in the footnote. Frequencies of the totally symmetric vibrations $\left(\mathrm{cm}^{-1}\right)$ of $\mathbf{F L}^{+}$and $\mathbf{H}^{+}-\mathbf{F L}$ cations calculated with DFT using the M06-2X functional and the cc-pVTZ basis set.

\begin{tabular}{|c|c|c|c|c|}
\hline$\lambda(\mathrm{nm})$ & $v\left(\mathrm{~cm}^{-1}\right)$ & $\Delta v\left(\mathrm{~cm}^{-1}\right)$ & & Assignment \\
\hline \multicolumn{5}{|l|}{$\mathbf{F L}^{+\mathrm{a}}$} \\
\hline 649.2 & 15404 & 0 & $0_{0}^{0}$ & $2{ }^{2} \mathrm{~B}_{1} \leftarrow \tilde{\mathrm{X}}^{2} \mathrm{~A}_{2}$ \\
\hline 640.4 & 15615 & 211 & $v_{21}$ & \\
\hline 632.0 & 15823 & 419 & $v_{20}$ & \\
\hline 592.9 & 16866 & 1463 & $v_{9}$ & \\
\hline \multicolumn{5}{|c|}{$\mathbf{H}^{+}-\mathbf{F L}^{\mathrm{b}}$} \\
\hline 423.3 & 23624 & 0 & $0_{0}^{0}$ & $2{ }^{1} \mathrm{~A}^{\prime} \leftarrow \tilde{\mathrm{X}}^{1} \mathrm{~A}^{\prime}$ \\
\hline 419.2 & 23855 & 231 & $v_{43}$ & \\
\hline 416.2 & 24027 & 403 & $v_{41}$ & \\
\hline 413.8 & 24166 & 542 & $v_{39}$ & \\
\hline 409.5 & 24420 & 796 & $v_{35}$ & \\
\hline 406.7 & 24588 & 964 & $v_{33}$ & \\
\hline 404.6 & 24716 & 1092 & $v_{30}$ & \\
\hline 402.7 & 24832 & 1208 & $v_{24}$ or $v_{25}$ & \\
\hline 399.8 & 25013 & 1389 & $v_{20}$ & \\
\hline 393.2 & 25432 & 1808 & $v_{20}+v_{41}$ & \\
\hline 391.4 & 25549 & 1925 & $v_{20}+v_{39}$ & \\
\hline
\end{tabular}

$\overline{{ }^{\mathrm{a}} \mathbf{F L}^{+}\left(\mathrm{C}_{2 \mathrm{~V}}\right) ;\left(\mathrm{a}_{1}\right) v_{1}-v_{21}: 3227,3225,3214,3201,1899,1680,1594,1525,1465,1420}$, 1357, 1253, 1189, 1169, 1113, 1028, 783, 720, 557, 415, 200.

${ }^{\mathrm{b}} \mathbf{H}^{+}$-FL (CS); (a') $v_{1}-v_{43}: 3759,3242,3235,3213,3212,3205,3201,3200,3172,1671$, $1681,1690,1667,1601,1530,1526,1495,1494,1439,1392,1326,1323,1290,1229$, $1209,1204,1197,1178,1122,1113,1056,1053,1029,921,786,743,638,623,560$, $508,423,275,208$. 
TABLE II. Electronic states, vertical excitation energies $(\mathrm{eV})$ and oscillator strengths (italics) of 9-fluorenone cation and protonated 9-fluorenone calculated with TD DFT/M06-2X/cc-pVTZ, SAC-CI/cc-pVDZ, and MS(5)CASPT2/cc-pVTZ using coordinates from DFT M06-2X/cc-pVTZ.

\begin{tabular}{lllllll}
\hline \hline State & \multicolumn{2}{c}{ TD DFT } & \multicolumn{2}{c}{ SAC-CI } & \multicolumn{2}{c}{ CASPT2 } \\
\hline $\mathbf{F L}^{+} \mathrm{C}_{2 \mathrm{v}}$ & & & & & & \\
$\tilde{\mathrm{X}}{ }^{2} \mathrm{~A}_{2}$ & 0.00 & & 0.00 & & 0.00 & \\
$1{ }^{2} \mathrm{~A}_{2}$ & 1.51 & 0.001 & 1.53 & 0.001 & 1.26 & 0.002 \\
$1{ }^{2} \mathrm{~B}_{1}$ & 1.68 & 0.0004 & 1.63 & 0.002 & 1.43 & 0.001 \\
$2{ }^{2} \mathrm{~B}_{1}$ & 2.09 & 0.18 & 2.34 & 0.320 & 2.14 & 0.150 \\
$3{ }^{2} \mathrm{~B}_{1}$ & 3.36 & 0.084 & 4.73 & 0.003 & 3.12 & 0.260 \\
$4{ }^{2} \mathrm{~B}_{1}$ & 4.52 & 0.014 & 6.26 & 0.120 & 4.21 & 0.000 \\
$1{ }^{2} \mathrm{~B}_{2}$ & 1.65 & 0.0000 & 1.20 & 0.000 & 1.48 & 0.000 \\
$\mathbf{H}^{-} \mathbf{F L}$ & & & & & & \\
$\tilde{\mathrm{X}}^{1} \mathrm{~A}^{\prime}$ & 0.00 & & 0.00 & & 0.00 & \\
$1{ }^{1} \mathrm{~A}^{\prime}$ & 2.19 & 0.003 & 1.54 & 0.001 & 2.00 & 0.021 \\
$2{ }^{1} \mathrm{~A}^{\prime}$ & 3.55 & 0.23 & 2.93 & 0.220 & 3.26 & 0.230 \\
$3{ }^{1} \mathrm{~A}^{\prime}$ & 4.24 & 0.003 & 3.75 & 0.002 & 3.94 & 0.004 \\
$4{ }^{1} \mathrm{~A}^{\prime}$ & 4.89 & 0.17 & 4.54 & 0.200 & 4.61 & 0.008 \\
$5{ }^{1} \mathrm{~A}^{\prime}$ & 5.49 & 0.88 & 5.14 & 0.930 & 4.77 & 0.085 \\
\hline \hline
\end{tabular}

${ }^{\text {a Spin contaminated state }\left\langle\mathrm{S}^{2}\right\rangle=0.9 \text { instead } 0.75 \text {. The active space in the CASPT }}$ calculations was $(11,12)$ for $\mathbf{F L}^{+}$and $(12,12)$ in case of $\mathbf{H}-\mathbf{F L} \mathbf{L}^{+}$

given in Table I is based on the ground state frequencies calculated at the DFT/M06-2X/cc-pVTZ level.

The absorption spectrum recorded after a mass-selective deposition of protonated fluorenone cation $\mathbf{H}-\mathbf{F L}^{+}, \mathrm{m} / \mathrm{z}=181$, shows an intense band at $423.3 \mathrm{~nm}$ with several weaker peaks between 390 and $420 \mathrm{~nm}$ (red trace, Figure 3). The double headed features separated by $20-25 \mathrm{~cm}^{-1}$ are evident for most of the peaks. This is due to trapping of the species at energetically non-equivalent neon sites. Thereafter, the matrix was exposed to $\lambda<260 \mathrm{~nm}$ photons. All the absorption bands diminished at the same rate on irradiation (black trace, Figure 3). This indicates that these absorptions belong to one electronic system with origin at $423.3 \mathrm{~nm}$ and the carrier is cationic. No new peaks appeared after irradiation.

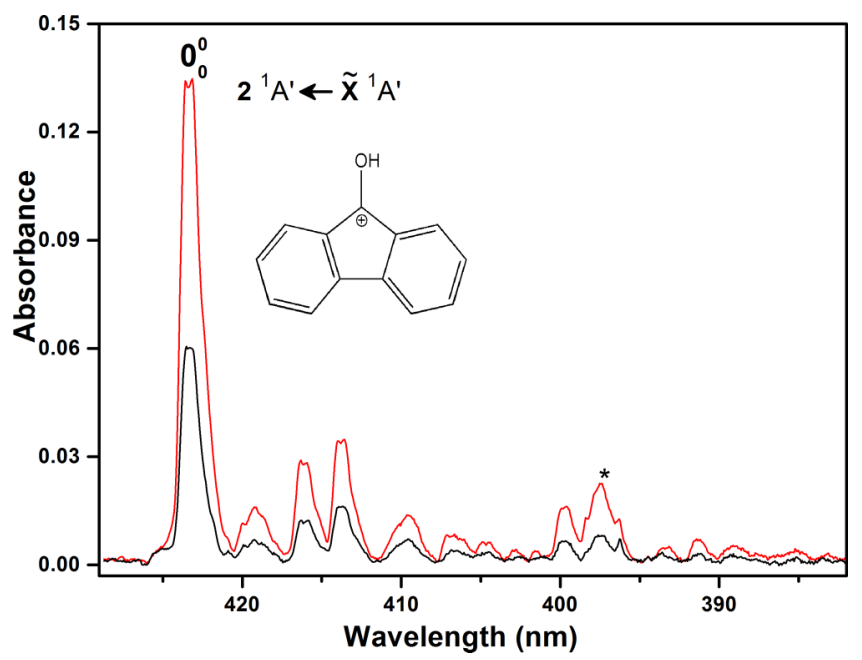

FIG. 3. Electronic absorption spectra recorded after deposition of $\mathrm{m} / \mathrm{z}=181$ cations produced by the proton transfer reaction of $\mathrm{EtOH}_{2}^{+}$with 9 -fluorenone in the source (red trace) and after irradiation of the matrix by $\lambda<260 \mathrm{~nm}$ photons (black trace). Asterisk marks the band of $\mathbf{H}-\mathbf{F L}^{+}$.
The absorptions recorded after depositing $\mathbf{H}-\mathbf{F L}^{+}$do not coincide with any band of $\mathbf{F L}^{+}$. The contribution of ${ }^{13} \mathrm{C}$ isotopologue of $\mathbf{F L}$ to $\mathbf{H}^{+}-\mathbf{F L}(\mathrm{m} / \mathrm{z}=181)$ ion current was negligible with higher pressure of ethanol in the source (black trace, Figure 1).

Calculations of the ground state energies of five plausible isomers of protonated fluorenone (Chart 2) indicate that structure $\mathbf{A}^{+}$is by far the most stable and expected to be the carrier of the $423 \mathrm{~nm}$ absorption system. Calculated vertical excitation energies of $\mathbf{A}^{+}$with TDDFT, SAC-CI, and MS(6)CASPT2 $\left(12,12\right.$ ) (Table II) predict a strong $2{ }^{1} \mathrm{~A}^{\prime} \leftarrow \tilde{\mathrm{X}}{ }^{1} \mathrm{~A}^{\prime}$ electronic transition at $3.55,2.93$, and $3.26 \mathrm{eV}$, respectively, and two others with energy $\sim 4.5$ and $\sim 5.5 \mathrm{eV}$ beyond the experimental detection range. Therefore, the $423 \mathrm{~nm}(2.92 \mathrm{eV})$ system is assigned to the $2{ }^{1} \mathrm{~A}^{\prime} \leftarrow \tilde{\mathrm{X}}{ }^{1} \mathrm{~A}^{\prime}$ transition of $\mathbf{A}^{+}$, fluorenone protonated on the oxygen. The $\mathbf{F L}^{+}$and $\mathbf{H}-\mathbf{F L}^{+}$ are characterized by electronic absorption spectroscopy for the first time. $\mathbf{H}-\mathbf{F L}^{+}$has been studied by NMR in a strong acidic solution. ${ }^{35}$

The resolved vibrational structure apparent in the $423 \mathrm{~nm}$ system of $\mathbf{H}-\mathbf{F L}^{+}$is due to excitation of a number of modes in the $2{ }^{1} \mathrm{~A}^{\prime}$ state. The assignment in Table I is based on the calculated ground state harmonic frequencies of $\mathbf{H}-\mathbf{F L}^{+}$.

After release of electrons into the matrix by UV irradiation, the neutral of structure $\mathbf{A}^{+}$was not observed. The TD DFT and SAC-CI methods predict a much weaker transition for $\mathbf{A}$ compared to $\mathbf{A}^{+}$(Table 1S.I in the supplementary material). ${ }^{38}$ As the neutrals are formed in the matrix by electron recombination in some percentage of the cations, the detection of a transition with such a low oscillator strength is not expected. Photofragmentation of the cation could also be another reason.

\section{B. Dibenzotropone cation and protonated dibenzotropone}

Mass-selected $\mathbf{D B T}^{+}(\mathrm{m} / \mathrm{z}=206)$ was deposited with neon containing a trace of $\mathrm{CH}_{3} \mathrm{Cl}$ as scavenger. Two absorption systems were observed commencing at $472.2 \mathrm{~nm}$ and $896.4 \mathrm{~nm}$

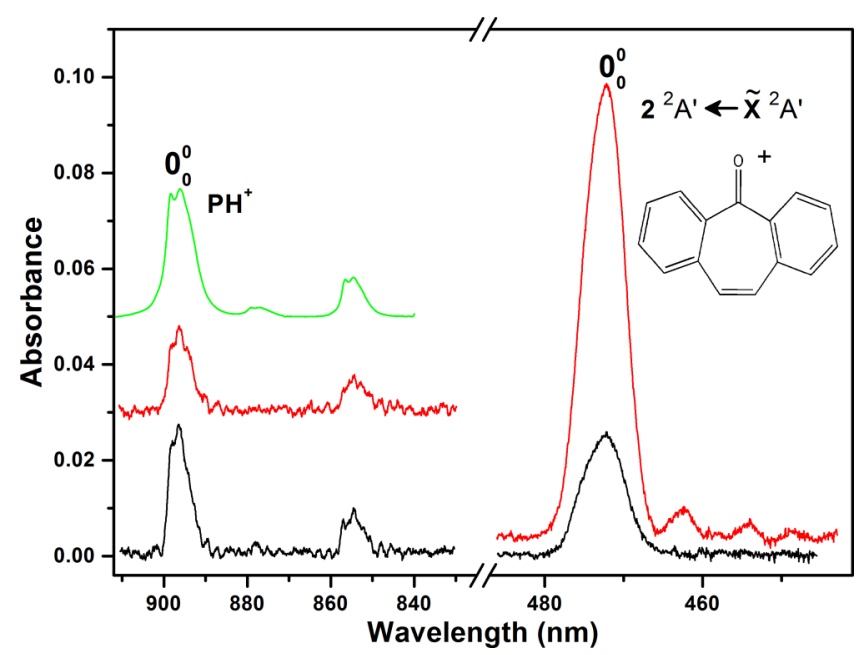

FIG. 4. Electronic absorption spectra recorded after deposition of 2,3,6,7dibenzotropone DBT $^{+}$into a neon matrix (red trace) and after photobleaching with UV photons, $\lambda<260 \mathrm{~nm}$ (black trace). Green trace shows the spectrum obtained after deposition of phenantrane cation $\mathbf{P H}^{+}$. 
(Figure 4, red trace). The $472 \mathrm{~nm}$ system decreased upon UV irradiation (black trace, right section) while the $896 \mathrm{~nm}$ one gained in intensity (black trace, right section). Thus, the former belongs to a cation, most likely $\mathbf{D B T}^{+}$, whereas the latter behaves in a way typical of a molecular fragment. The $896 \mathrm{~nm}$ absorption system is that of phenanthrene cation $\mathbf{P H}^{+}$(structure is shown in Chart 1$) ;{ }^{36}$ the spectrum of the mass-selected $\mathbf{P H}^{+}$is shown in green trace of Figure 4. Thus, $\mathbf{D B T}^{+}$fragments to $\mathbf{P H}{ }^{+}$and $\mathrm{CO}$ during deposition. $\mathbf{D B T}{ }^{+}$is also photochemically unstable as it produced $\mathbf{P H}^{+}$upon UV irradiation. Release of $\mathrm{CO}$ from trapped ketones in a neon matrix upon UV exposure has been observed previously. ${ }^{37}$

DBT has been studied by PE spectroscopy and semiempirical calculations indicated that the ground state of $\mathbf{D B T}^{+}$ has ${ }^{2} \mathrm{~B}_{1}$ symmetry. ${ }^{16}$ In the PE spectrum, a band lying at 2.64 $\mathrm{eV}$ above the ground state of the cation is present. This energy is close to the $472 \mathrm{~nm}(2.63 \mathrm{eV})$ system observed in a neon matrix after deposition of $\mathbf{D B T}^{+}$. Optimization of the ground state geometry revealed that the cation as well as neutral molecule has a saddle point at $\mathrm{C}_{2 \mathrm{v}}$ symmetry and a real minimum at $\mathrm{C}_{\mathrm{s}}$. Nevertheless, the $\mathrm{C}_{2 \mathrm{v}}$ coordinates were used for the vertical excitation energy calculations. TD DFT, SAC-CI, and MS(5)CASPT2 all predict a strong $2{ }^{2} \mathrm{~A}_{2} \leftarrow \tilde{\mathrm{X}}^{2} \mathrm{~B}_{1}$ transition with energy $1.86-2.03 \mathrm{eV}$ ( $f=0.12-0.26$ ). As no absorption was detected in the near infrared, the calculated vertical energy and/or the oscillator strength of the $2{ }^{2} \mathrm{~A}_{2} \leftarrow \tilde{\mathrm{X}}^{2} \mathrm{~B}_{1}$ transition are overestimated.

The TD DFT, CASPT2, and SAC-CI indicate a moderately intense $2^{2} \mathrm{~B}_{1} \leftarrow \tilde{\mathrm{X}}^{2} \mathrm{~B}_{1}$ transition with energy 3.15 , 3.13 , and $3.52 \mathrm{eV}$ (Table III), respectively; the two former methods also give an even stronger $3^{2} \mathrm{~A}_{2} \leftarrow \tilde{\mathrm{X}}^{2} \mathrm{~B}_{1}$ transition at 3.26 and $2.95 \mathrm{eV}$. The $3^{2} \mathrm{~A}_{2}$ state of $\mathbf{D B T}^{+}$can only be accessed from the ground state of DBT via a two photon process (see Section 1 in the supplementary material), ${ }^{38}$ therefore, the state obtained at $2.64 \mathrm{eV}$ by the PE study does not correspond to $3{ }^{2} \mathrm{~A}_{2}$. Hence, the band present in PE spectrum of DBT at $2.64 \mathrm{eV}$ corresponds to the $2{ }^{2} \mathrm{~B}_{1}$ state of the cation and the absorption starting at $472 \mathrm{~nm}(2.63 \mathrm{eV})$ belongs to the $2{ }^{2} \mathrm{~B}_{1} \leftarrow \tilde{\mathrm{X}}{ }^{2} \mathrm{~B}_{1}$ electronic transition of $\mathbf{D B T}^{+}$. The CASPT2 calculations provide the best estimate of the energy of this transition, overestimate by $0.5 \mathrm{eV}$. Vertical excitation energies calculated with the coordinates optimized at $\mathrm{C}_{\mathrm{s}}$ symmetry give similar results (Table II). As the DBT $^{+}$is not planar, the $472 \mathrm{~nm}$ system is assigned to the $2^{2} \mathrm{~A}^{\prime} \leftarrow \tilde{\mathrm{X}}^{2} \mathrm{~A}^{\prime}$ electronic transition (corresponding to $2{ }^{2} \mathrm{~B}_{1} \leftarrow \tilde{\mathrm{X}}^{2} \mathrm{~B}_{1}$ in higher symmetry).

The electronic spectrum of $\mathbf{D B T}^{+}$is simple and consists of a strong origin band at $472.2 \mathrm{~nm}$ and two weaker vibrational bands lying $445,845 \mathrm{~cm}^{-1}$ to the blue. The assignment is based on the calculated ground state frequencies (Table IV).

Two electronic systems starting at 502.3 and $371.5 \mathrm{~nm}$ were detected after mass-selected deposition of the $m / z=207$, H-DBT ${ }^{+}$cations (red trace, Figure 5). Resolved vibrational structure is apparent for both electronic systems. Exposition of the matrix to $\lambda<260 \mathrm{~nm}$ photons caused a decrease in intensity for all the bands (black trace) implying cationic carrier. The rate of decrement suggests that the 502.3 and $371.5 \mathrm{~nm}$ absorption systems are of same $\mathbf{H}-\mathbf{D B} \mathbf{T}^{+}$isomer.

As in the case of $\mathbf{H}^{+}-\mathbf{F L}$, protonation on the oxygen site gives the most stable isomer $\mathbf{F}^{+}$of $\mathbf{H}^{+}$-DBT which is believed
TABLE III. Electronic states, vertical excitation energies (eV) and oscillator strengths (italics) of 2,3,6,7-dibenzotropone cation $\mathbf{D B T}^{+}$and protonated dibenzotropone $\mathbf{H}-$ DBT $^{+}$calculated at the TD DFT/M06-2X/cc-pVTZ, SAC-CI/cc-pVDZ, and MS(5)-CASPT2/cc-pVDZ level using coordinates from DFT M06-2X/cc-pVTZ. The active space used in CASPT2 calculations was $(11,11)$ for $\mathbf{D B T}^{+}$and $(10,10)$ for $\mathbf{H}-\mathbf{D B} \mathbf{T}^{+}$.

\begin{tabular}{|c|c|c|c|c|c|c|}
\hline \multirow{2}{*}{$\begin{array}{l}\text { State } \\
\text { DBT }^{+} \mathbf{C}\end{array}$} & \multicolumn{2}{|c|}{ TD DFT } & \multicolumn{2}{|c|}{ SAC-CI } & \multicolumn{2}{|c|}{ CASPT2 } \\
\hline & & & & & & \\
\hline$\tilde{\mathrm{X}}^{2} \mathrm{~B}_{1}$ & 0.00 & & 0.00 & & 0.00 & \\
\hline $1^{2} \mathrm{~B}_{1}$ & 1.65 & 0.0013 & 1.64 & 0.002 & 1.47 & 0.001 \\
\hline $2{ }^{2} \mathrm{~B}_{1}$ & 3.15 & 0.033 & 3.52 & 0.075 & 3.13 & 0.017 \\
\hline $1^{2} \mathrm{~A}_{2}$ & 1.79 & 0.0066 & 1.82 & 0.002 & 1.53 & 0.025 \\
\hline $2{ }^{2} \mathrm{~A}_{2}$ & 1.86 & 0.13 & 2.03 & 0.260 & 1.92 & 0.120 \\
\hline $3{ }^{2} \mathrm{~A}_{2}$ & 3.26 & 0.32 & 5.13 & 0.000 & 2.95 & 0.550 \\
\hline $1^{2} \mathrm{~B}_{2}$ & 1.77 & 0.0000 & 1.62 & 0.000 & 1.48 & 0.000 \\
\hline \multicolumn{7}{|c|}{$\mathbf{D B T}^{+} \mathrm{C}_{\mathrm{s}}$} \\
\hline$\tilde{X}^{2} A^{\prime}$ & 0.00 & & 0.00 & & 0.00 & \\
\hline $1^{2} \mathrm{~A}^{\prime}$ & 1.74 & 0.0017 & 1.72 & 0.002 & 1.50 & 0.002 \\
\hline $2{ }^{2} \mathrm{~A}^{\prime}$ & 3.15 & 0.038 & 3.51 & 0.072 & 3.09 & 0.013 \\
\hline $3^{2} \mathrm{~A}^{\prime}$ & 4.02 & 0.0002 & 4.85 & 0.007 & 4.12 & 0.020 \\
\hline $4^{2} \mathrm{~A}^{\prime}$ & 4.30 & 0.0014 & 5.46 & 0.001 & 4.41 & 0.005 \\
\hline $1^{2} \mathrm{~A}^{\prime \prime}$ & 1.53 & 0.081 & 1.40 & 0.005 & 1.40 & 0.003 \\
\hline $2^{2} \mathrm{~A}^{\prime \prime}$ & 1.95 & 0.065 & 1.85 & 0.034 & 1.70 & 0.280 \\
\hline $3^{2} \mathrm{~A}^{\prime \prime}$ & 3.34 & 0.31 & 2.07 & 0.220 & 3.28 & 0.510 \\
\hline $4^{2} \mathrm{~A}^{\prime \prime}$ & 3.82 & 0.0084 & 4.76 & 0.000 & 4.19 & 0.000 \\
\hline $5^{2} \mathrm{~A}^{\prime \prime}$ & 3.97 & 0.0038 & 5.15 & 0.001 & 4.73 & 0.003 \\
\hline $6^{2} \mathrm{~A}^{\prime \prime}$ & 4.99 & 0.0009 & 5.28 & 0.000 & 5.04 & 0.003 \\
\hline \multicolumn{7}{|c|}{ H-DBT ${ }^{+} \mathrm{C}_{1}$} \\
\hline$\tilde{\mathrm{X}}^{1} \mathrm{~A}$ & 0.00 & & 0.00 & & 0.00 & \\
\hline $1^{1} \mathrm{~A}$ & 3.06 & 0.058 & 2.23 & 0.059 & 3.01 & 0.084 \\
\hline $2{ }^{1} \mathrm{~A}$ & 3.76 & 0.005 & 3.29 & 0.032 & 3.84 & 0.140 \\
\hline $3{ }^{1} \mathrm{~A}$ & 4.28 & 0.21 & 3.67 & 0.096 & 4.41 & 0.180 \\
\hline $4{ }^{1} \mathrm{~A}$ & 4.82 & 1.13 & 4.45 & 1.430 & 4.80 & 1.170 \\
\hline $5^{1} \mathrm{~A}$ & 4.88 & 0.13 & 4.57 & 0.016 & 5.05 & 0.140 \\
\hline $6{ }^{1} \mathrm{~A}$ & 5.23 & 0.055 & 4.86 & 0.047 & 5.45 & 0.003 \\
\hline
\end{tabular}

to be absorber. TD DFT and CASPT2 predict two ${ }^{1} \mathrm{~A}$ electronic states below $4 \mathrm{eV}$, whereas SAC-CI three (Table III). The two former methods locate a moderately intense lowest energy $1{ }^{1} \mathrm{~A} \leftarrow \tilde{\mathrm{X}}{ }^{1} \mathrm{~A}$ transition around $3 \mathrm{eV}$, while the latter at 2.23 $\mathrm{eV}$, comparable with $502 \mathrm{~nm}(2.47 \mathrm{eV})$ system. The TD DFT and CASPT2 calculations overestimate the observed value by $\sim 0.5 \mathrm{eV}$. The $502 \mathrm{~nm}$ system is assigned to the $1{ }^{1} \mathrm{~A} \leftarrow \tilde{\mathrm{X}}{ }^{1} \mathrm{~A}$ transition of $\mathbf{H}-\mathrm{DBT}^{+}$. According to TD DFT, the transition to the $2{ }^{1} \mathrm{~A}$ state is expected around $3.76 \mathrm{eV}$ with $\mathrm{f}=0.005$, next is at $4.28 \mathrm{eV}$ with $\mathrm{f}=0.21$. SAC-CI and CASPT2 give the $2{ }^{1} \mathrm{~A} \leftarrow \tilde{\mathrm{X}}{ }^{1} \mathrm{~A}$ transition at $3.29 \mathrm{eV}(\mathrm{f}=0.032)$ and $3.84 \mathrm{eV}$ ( $\mathrm{f}=0.14)$, respectively, which can be compared with $3.34 \mathrm{eV}$ $(371.5 \mathrm{~nm})$ in the spectrum. The assignment of the vibrational bands (Table IV) is made on the basis of calculated ground state harmonic vibrational frequencies of $\mathbf{H}$-DBT ${ }^{+}$.

Though no new bands were detected after neutralization of the trapped cations, the expected electronic transitions of $\mathbf{F}$ were calculated (Table 1S.I in the supplementary material). ${ }^{38}$ The TD DFT results are less reliable because the wavefunctions of the excited states are spin contaminated: $\left\langle\mathrm{S}^{2}\right\rangle$ is $>0.9$ instead of 0.75. SAC-CI predicts two electronic transitions at 3.63 and $4.08 \mathrm{eV}$ with an intensity similar as for $\mathbf{H}-\mathbf{D B T}^{+}$. If 
TABLE IV. Absorption band maxima $( \pm 0.1 \mathrm{~nm})$ of electronic transitions of 2,3,6,7-dibenzotropone cation $\mathbf{D B T}^{+}$and protonated dibenzotropone H-DBT $^{+}$in $6 \mathrm{~K}$ neon matrices and assignment based on the vibrational frequencies of the normal modes listed in the footnote. Frequencies of the totally symmetric vibrations $\left(\mathrm{cm}^{-1}\right)$ of $\mathbf{D B T} \mathbf{T}^{+}$and $\mathbf{H}-\mathbf{D B T ^ { + }}$ calculated with DFT using the M06-2X functional and the cc-pVTZ basis set.

\begin{tabular}{lcccc}
\hline \hline$\lambda(\mathrm{nm})$ & $v\left(\mathrm{~cm}^{-1}\right)$ & $\Delta v\left(\mathrm{~cm}^{-1}\right)$ & & Assignment \\
\hline $\mathbf{D B T}^{+\mathrm{a}}$ & & & & \\
472.2 & 21177 & 0 & $0_{0}^{0}$ & $2{ }^{2} \mathrm{~A}^{\prime} \leftarrow \tilde{\mathrm{X}}^{2} \mathrm{~A}^{\prime}$ \\
462.5 & 21622 & 445 & $v_{31}$ & \\
454.1 & 22022 & 845 & $v_{23}$ or $v_{24}$ & \\
& & & & \\
H-DBT $^{+\mathrm{b}}$ & & & 0 & $1{ }^{1} \mathrm{~A} \leftarrow \tilde{\mathrm{X}}{ }^{1} \mathrm{~A}$ \\
502.4 & 19904 & 0 & $0_{0}^{0}$ & \\
493.3 & 20272 & 368 & $v_{67}$ & \\
474.3 & 21084 & 1180 & $v_{33}$ or $v_{34}$ & \\
470.3 & 21263 & 1359 & $v_{25}$ & \\
466.0 & 21459 & 1555 & $v_{16}$ or $v_{17}$ & \\
371.5 & 26918 & 0 & $0_{0}^{0}$ & $2{ }^{1} \mathrm{~A} \leftarrow \tilde{\mathrm{X}}{ }^{1} \mathrm{~A}$ \\
358.1 & 27925 & 1007 & $v_{43}$ & \\
353.6 & 28281 & 1363 & $v_{25}$ & \\
\hline \hline
\end{tabular}

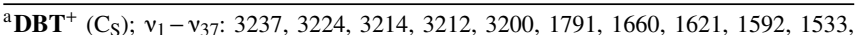
$1468,1406,1352,1273,1206,1195,1190,1124,1076,1059,1029,953,887,838,819$, 792, 682, 674, 589, 511, 468, 400, 318, 253, 209, 125, 44.

${ }^{\mathrm{b}} \mathbf{H}_{-\mathbf{D B T}^{+}}\left(\mathrm{C}_{1}\right) ; v_{1}-v_{75}: 3810,3248,3228,3218,3218,3211,3208,3203,3199,3193$, $3189,1700,1679,1674,1614,1598,1548,1533,1529,1495,1480,1447,1437,1407$, $1392,1318,1230,1282,1264,1235,1219,1215,1207,1191,1169,1141,1095,1082$, 1062, 1056, 1048, 1030, 1016, 941, 936, 920, 877, 862, 841, 832, 799, 782, 757, 735, 697, 687, 625, 604, 587, 579, 555, 516, 497, 478, 422, 413, 384, 331, 324, 270, 218, $195,138,80,50$.

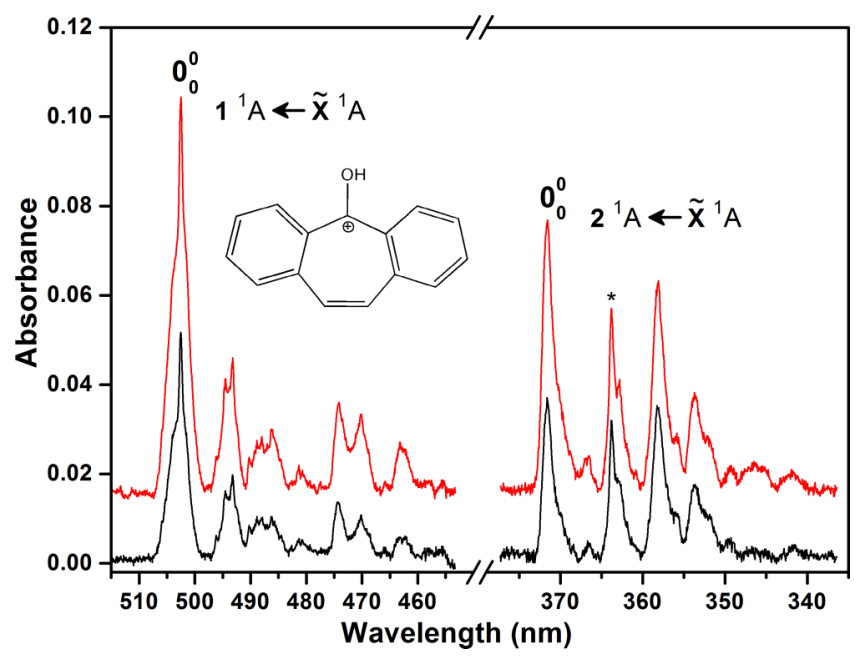

FIG. 5. Electronic absorption spectra recorded after depositing $\mathrm{m} / \mathrm{z}=207$ cations produced by protonation of 2,3,6,7-dibenzotropone in the source using ethanol (red trace), and after irradiation of the matrix by $\lambda<260 \mathrm{~nm}$ photons (black trace).

the oscillator strengths are correct the neutral should also be detected, in contrast to the observation. Protofragmentation of the cations could be the reason for the lack of detection of $\mathbf{F}$.

\section{CONCLUDING REMARKS}

The studied O-PAH class of molecules is astrobiologically interesting as they have been found in lipids, vitamins, pigment, and are involved in electron transport. Aromatic ketones are also present in plants, fungi, lichens. Identification of 9-fluorenone in Murchison meteorite suggests that such aromatic ketones can be present on cosmic ices; ice photolysis in astronomical environments is believed to be the leading chemical process for the formation of the oxidized PAHs. They may also be found in the gas phase because complex organics detected in the interstellar medium are thought to be formed in cold grain surfaces and thereafter delivered into gas phase through ablation by shock waves or heating from stars/supernova. Spectroscopic knowledge is required for the in situ detection of such molecules and this work provides the data on the protonated O-PAHs systems in inert neon matrices at $6 \mathrm{~K}$ and is a starting point for gas phase studies.

\section{ACKNOWLEDGMENTS}

This work was supported by the Swiss National Science Foundation (Project No. 200020-124349/1). J.F. is grateful to Professor Roland Lindh from the Uppsala University for a fruitful discussion. Calculations were performed at sciCORE (http://scicore.unibas.ch/) scientific computing core facility at the University of Basel.

${ }^{1}$ L. J. Allamandola, D. J. Hudgins, and S. A. Sandford, Astrophys. J. 511, L115 (1999).

${ }^{2}$ L. J. Allamandola, S. A. Sandford, and B. Wopenka, Science 237, 56 (1987).

${ }^{3}$ M. K. Crawford, A. G. G. M. Tielens, and L. J. Allamandola, Astrophys. J. 293, L45 (1985).

${ }^{4}$ T. Onaka, I. Yamamura, T. Tanabe, T. L. Roellig, and L. Yuen, Publ. Astron. Soc. Jpn. 48, L59 (1996).

${ }^{5}$ J. Kahanpää, K. Mattila, K. Lehtinen, C. Leinert, and D. Lemke, Astron. Astrophys. 405, 999 (2003).

${ }^{6}$ I. Sakon, T. Onaka, D. Ishihara, T. Ootsubo, I. Yamamura, T. Tanabé, and T. L. Roellig, Astrophys. J. 609, 203 (2004).

${ }^{7}$ M. P. Bernstein, J. E. Elsila, J. P. Dworkin, S. A. Sandford, L. J. Allamandola, and R. N. Zare, Astrophys. J. 576, 1115 (2002).

${ }^{8}$ S. F. M. Ashbourn, J. E. Elsila, J. P. Dworkin, M. P. Bernstein, S. A. Sandford, and L. J. Allamandola, Meteorit. Planet. Sci. 42, 2035 (2007).

${ }^{9}$ E. E. Hardegree-Ullman, M. S. Gudipati, A. C. A. Boogert, H. Lignell, L. J. Allamandola, K. R. Stapelfeldt, and M. Werner, Astrophys. J. 784, 172 (2014).

${ }^{10}$ M. P. Bernstein, S. A. Sandford, L. J. Allamandola, J. S. Gillette, S. J. Clemett, and R. N. Zare, Science 283, 1135 (1999).

${ }^{11}$ M. P. Bernstein, S. A. Sandford, A. L. Mattioda, and L. J. Allamandola, Astrophys. J. 664, 1264 (2007).

${ }^{12}$ J. Bouwman, H. M. Cuppen, A. Bakker, L. J. Allamandola, and H. Linnartz, Astron. Astrophys. 511, A33 (2010).

${ }^{13}$ P. J. Sarre, J. Mol. Spectrosc. 238, 1 (2006).

${ }^{14}$ F.-X. Hardy, O. Gause, C. A. Rice, and J. P. Maier, Astrophys. J. 778, L30 (2013).

${ }^{15}$ C. A. Rice, F.-X. Hardy, O. Gause, and J. P. Maier, J. Phys. Chem. Lett. 5, 942 (2014).

${ }^{16}$ M. Allan, E. Heilbronner, and E. Kloster-Jensen, J. Electron Spectrosc. Relat. Phenom. 6, 181 (1975).

${ }^{17}$ B. P. Balise, B. S. Middleditch, and J. Oro, Org. Geochem. 5, 211 (1984).

${ }^{18}$ R. V. Krishnamurthy, J. R. Cronin, S. Pizzarello, and G. U. Yuen, Geochim. Cosmochim. Acta 56, 4045 (1992).

${ }^{19}$ G. D. Cody and C. M. Alexander, Geochim. Cosmochim. Acta 69, 1085 (2005).

${ }^{20}$ A. L. Knecht, B. C. Goodale, L. Truong, M. T. Simonich, A. J. Swanson, M. M. Matzke, K. A. Anderson, K. M. Waters, and R. L. Tanguay, Toxicol. Appl. Pharmacol. 271, 266 (2013).

${ }^{21}$ J. Konig, E. Balfanz, W. Funcke, and T. Romanowsk, Anal. Chem. 55, 599 (1983).

${ }^{22}$ E. M. Fitzpatrick, A. B. Ross, J. Bates, G. Andrews, J. M. Jones, H. Phylaktou, M. Pourkashanian, and A. Williams, Process Saf. Environ. Prot. 85, 430 (2007).

${ }^{23}$ I. Garkusha, J. Fulara, P. J. Sarre, and J. P. Maier, J. Phys. Chem. A 115, 10972 (2011).

${ }^{24}$ R. Rossetti and L. E. Brus, Rev. Sci. Instrum. 51, 467 (1980). 
${ }^{25}$ M. J. Frisch, G. W. Trucks, H. B. Schlegel, G. E. Scuseria, M. A. Robb, J. R. Cheeseman, G. Scalmani, V. Barone, B. Mennucci, G. Petersson et al., GaUssian 09, Revision D.01, Gaussian Inc., Wallingford, CT, 2009.

${ }^{26}$ Y. Zhao and D. G. Truhlar, Theor. Chem. Acc. 120, 215 (2008).

${ }^{27}$ A. Y. Rogachev, A. S. Filatov, A. V. Zabula, and M. A. Petrukhina, Phys. Chem. Chem. Phys. 14, 3554 (2012).

${ }^{28}$ H. Nakatsuji and K. Hirao, J. Chem. Phys. 68, 2053 (1978).

${ }^{29}$ H. Nakatsuji, Chem. Phys. Lett. 67, 329 (1979).

${ }^{30}$ J. Finley, P.-Å Malmqvist, B. O. Roos, and L. Serrano-Andrés, Chem. Phys. Lett. 288, 299 (1998).

${ }^{31}$ F. Aquilante, L. De Vico, N. Ferré, G. Ghigo, P.-Å Malmqvist, P. Neogrády, T. B. Pedersen, M. Pitonak, M. Reiher, B. O. Roos, L. Serrano-Andrés, M. Urban, V. Veryazov, and R. Lindh, J. Comput. Chem. 31, 224 (2010).

${ }^{32}$ A. I. Adeogun, N. W. Odozi, N. O. Obiegbedi, and O. S. Bello, Afr. J. Biotechnol. 7, 2736 (2008).
${ }^{33}$ K. K. Ding and C. P. Pan, Crystallogr. Rep. 58, 604 (2013).

${ }^{34}$ G. Centineo, I. Fragala, G. Bruno, and S. Spampinato, J. Mol. Struct. 44, 203 (1978).

${ }^{35}$ G. A. Olah, G. K. Surya prakash, G. Liang, P. W. Westerman, K. Kunde, J. Chandrasekhar, and P. V. R. Schleyer, J. Am. Chem. Soc. 102, 4485 (1980).

${ }^{36}$ A. Chakraborty, J. Fulara, and J. P. Maier, J. Phys. Chem. A 109, 50 (2015).

${ }^{37}$ F. Salama, C. Joblin, and L. J. Allamandola, J. Chem. Phys. 101, 10252 (1994).

${ }^{38}$ See supplementary material at http://dx.doi.org/10.1063/1.4929484 for the HOMO and LUMO energies of DBT and $\mathrm{DBT}^{+}$(Figure 1S.I, Figure 1S.II), discussion on computational discrepancy (Section 1S), optimized coordinates used for excitation energy calculations (Chart 1S), and calculated vertical excitation energies of H-FL and H-DBT (Table 1S.I). 